\title{
Matrix Metalloproteinase Inhibitor COL-3 Prevents the Development of Paclitaxel-Induced Hyperalgesia in Mice
}

\author{
Subramanian S. Parvathy Willias Masocha \\ Department of Pharmacology and Therapeutics, Faculty of Pharmacy, Health Sciences Center, Kuwait University, \\ Jabriya, Kuwait
}

\begin{abstract}
Key Words
Paclitaxel $\cdot$ Chemotherapy-induced peripheral neuropathy • Pain - Prevention - Chemically modified tetracycline .

$\mathrm{COL}-3 \cdot$ Matrix metalloproteinase inhibitor $\cdot$ Cytokine $\cdot$

Chemokine
\end{abstract}

\begin{abstract}
Objective: To study the potential of chemically modified tetracycline-3 (COL-3), a potent matrix metalloproteinase (MMP) inhibitor, to protect against the development of paclitaxel-induced painful neuropathy and its immunomodulatory effects. Materials and Methods: The reaction latency to thermal stimuli (hot plate test) of female BALB/c mice was recorded before and after treatment with paclitaxel $(2 \mathrm{mg} /$ kg i.p.), paclitaxel plus COL-3 (4, 20 or $40 \mathrm{mg} / \mathrm{kg}$ p.o.) or their vehicles for 5 consecutive days. Gene transcripts of CD11b (marker for microglia), 5 cytokines (IFN- $\gamma$, IL-1 $\beta$, IL-6, IL-10 and TNF- $\alpha$ ) and 3 chemokines (CCL2, CXCL10 and CX3CL1) were quantified by real-time PCR in the brains, spinal cords and spleens of mice sacrificed on day 7 after treatment. Results: Treatment with paclitaxel reduced the reaction latency time to thermal stimuli (thermal hyperalgesia) for 4 weeks, with maximum effect on days 7 and 10. The coadministration of paclitaxel with COL-3 $40 \mathrm{mg} / \mathrm{kg}$, but not lower doses, prevented the development of paclitaxel-induced thermal hyperalgesia. Treatment with paclitaxel alone or coadministration with COL-3 increased CD11b transcript levels in the
\end{abstract}

brain but not in the spinal cord. Treatment with paclitaxel reduced IL- 6 transcript levels in the spinal cord but did not alter the transcript levels of other cytokines or chemokines in the brain, spinal cord or spleen. The coadministration of COL-3 with paclitaxel significantly increased the transcript levels of IL- 6 in the spleen and decreased CX3CL1 transcripts in the brain in comparison to treatment with paclitaxel alone. Conclusion: Our results indicate that the MMP inhibitor COL3 protected against paclitaxel-induced thermal hyperalgesia and, thus, could be useful in the prevention of chemotherapy-induced painful neuropathy.

Copyright $\odot 2012$ S. Karger AG, Base

\section{Introduction}

Taxanes such as paclitaxel $\left(\operatorname{Taxol}^{\circledR}\right)$, which are mitotic spindle inhibitors [1], are fundamental in the treatment of breast cancer and other solid tumors. However, their use is hampered by the development of dose-limiting painful peripheral neuropathy $[2,3]$. Paclitaxel preferentially impairs sensory fibers and produces neuropathy in the distal extremities, hands and feet, presenting in a glove-stocking pattern [4]. This peripheral neuropathy presents as a chronic painful neuropathic syndrome in some patients.

In rodent models paclitaxel-induced neuropathic pain (PINP) manifests as mechanical allodynia or thermal

\section{KARGER}

Fax +4161306 1234

E-Mail karger@karger.ch

www.karger.com
(C) 2012 S. Karger AG, Basel

$1011-7571 / 13 / 0221-0035 \$ 38.00 / 0$

Accessible online at:

www.karger.com/mpp
Willias Masocha

Department of Pharmacology and Therapeutics, Faculty of Pharmacy

Health Sciences Center, Kuwait University

PO Box 24923, 13110 Safat (Kuwait)

Tel. +9652498 6078, E-Mail masocha@ @sc.edu.kw 
hyperalgesia [3, 5-7]. Various pathogenetic mechanisms have been proposed to play a role in the development of PINP, including glial cell activation in the central nervous system $[8,9]$. Cytokines might also be involved in the pathogenesis of PINP since paclitaxel has been shown to induce cytokine expression $[10,11]$ and the administration of cytokines such as IL- 6 and IL-10 has been reported to prevent the development of or attenuate PINP $[5,11]$. Recent studies implicate matrix metalloproteinases (MMPs) and proteinase-activated receptors in the development of PINP $[12,13]$.

Taking into consideration the recently suggested role of MMPs in the development of PINP, we evaluated the potential of COL-3 (6-demethyl-6-deoxy-4-dedimethylaminotetracycline), also known as CMT-3, a potent MMP inhibitor [14-16], to prevent the development of PINP.

\section{Animals and Methods}

\section{Animals}

All animals $(\mathrm{n}=166)$ used in this study were female BALB/c mice (8-12 weeks old; 20-30 g) supplied by the Animal Resources Center at the Health Sciences Center, Kuwait University, Kuwait. The mice were kept in temperature-controlled $\left(24 \pm 1^{\circ} \mathrm{C}\right)$ rooms with food and water ad libitum. All experiments were performed during the same period of the day (8:00 a.m. to 4:00 p.m.) to exclude diurnal variations in pharmacological effects. The animals were handled in compliance with European Communities Council Directive 86/609 for the care of laboratory animals and ethical guidelines for research in experimental pain with conscious animals [17].

\section{Drug Treatment and Assessment of Thermal Nociception}

Paclitaxel (Tocris, Bristol, UK) was dissolved in a solution made up of $50 \%$ Cremophor EL and $50 \%$ absolute ethanol to a concentration of $6 \mathrm{mg} / \mathrm{ml}$ and stored at $-20^{\circ} \mathrm{C}$ for a maximum of 14 days. It was then diluted in normal saline $(\mathrm{NaCl} 0.9 \%)$ to a final concentration of $0.2 \mathrm{mg} / \mathrm{ml}$ just before administration. The vehicle for paclitaxel was diluted at the time of injection with normal saline in the same proportion as the paclitaxel solution. Paclitaxel $2 \mathrm{mg} / \mathrm{kg}$ or its vehicle were administered to the mice intraperitoneally, in a volume of $10 \mathrm{ml} / \mathrm{kg}$, once per day for 5 consecutive days. This treatment regimen has been reported to produce painful neuropathy in mice [6].

COL-3 (a gift from Galderma, Research and Development SNC, Les Templier, France) was dissolved in 1\% methylcellulose and administered to mice by oral gavage in a volume of $12.5 \mathrm{ml} /$ $\mathrm{kg}$ body mass. COL-3 (4-40 mg/kg) was coadministered with paclitaxel or its vehicle daily for 5 days. The mice were assessed for the development of neuropathic pain (thermal hyperalgesia) and those that received paclitaxel plus COL-3 were compared with the mice treated with the paclitaxel plus vehicle (for COL-3) only.

Reaction latencies to the hot plate test were measured before treatment (baseline latency) and on days 7, 10, 14, 17, 21 and 28 after the first injection of drugs (paclitaxel or COL-3). Briefly, the mice were individually placed on a hot plate (Panlab SL, Barcelona, Spain) with the temperature adjusted to $55 \pm 1{ }^{\circ} \mathrm{C}$. The time to the first sign of nociception, paw licking, flinching or jump response to avoid the heat was recorded and the animal immediately removed from the hot plate. A cutoff period of $20 \mathrm{~s}$ was maintained to avoid damage to the paws. The observer (S.S.P.) was blinded to the treatment the animal received. The percentage change in reaction latency was calculated as follows: [(response latency after drug treatment - pretreatment baseline latency)/pretreatment baseline latency] $\times 100$.

\section{Gene Expression Analysis by Real-Time PCR}

Gene transcripts of CD11b (a marker for microglia), 5 cytokines (IFN- $\gamma$, IL-1 $\beta$, IL- 6 , IL-10 and TNF- $\alpha$ ) and 3 chemokines (CCL2, CXCL10 and CX3CL1) were quantified by real-time PCR in the brains, spinal cords and spleens dissected out from the mice sacrificed at 7 days after the first administration of the vehicle, paclitaxel or paclitaxel plus COL-3 $40 \mathrm{mg} / \mathrm{kg}$. Total RNA was extracted from half of the fresh frozen brains and reverse-transcribed as described previously [18]. The transcript levels were quantified on an ABI Prism ${ }^{\circledR} 7500$ sequence detection system (Applied Biosystems, Foster City, Calif., USA) as previously described [19]. The primer sequences which were used, listed in table 1, were ordered from Invitrogen (Life Technologies, Carlsbad, Calif., USA). Threshold cycle $\left(\mathrm{C}_{\mathrm{t}}\right)$ values for all cDNA samples were obtained and the amount of transcripts of individual animal samples ( $n=4-6$ per group) was normalized to cyclophilin $\left(\Delta C_{t}\right)$. The relative amount of target gene transcripts was calculated using the $2^{-\Delta \Delta \mathrm{Ct}}$ method as described previously [20]. These values were then used to calculate the mean and standard error (SEM) of the relative expression of the target gene mRNA in the brain of the drug- and vehicle-treated mice.

\section{Statistical Analyses}

Statistical analyses were performed using the unpaired $t$ test with Welch's correction, one-way ANOVA followed by NewmanKeuls multiple comparison test or two-way repeated measures ANOVA followed by Bonferroni posttests. The differences were considered significant at $p<0.05$. The results in the text and figures are expressed as the means \pm SEM.

\section{Results}

\section{Paclitaxel-Induced Thermal Hyperalgesia}

Paclitaxel produced a significant reduction in response latency time to thermal stimuli (thermal hyperalgesia) from 7 to 28 days after the first drug administration compared to the baseline latency and from 7 to 21 days compared to the vehicle-only-treated animals in the hot plate test $(\mathrm{p}<0.01$; fig. 1$)$.

\section{COL-3 Prevents the Development of}

Paclitaxel-Induced Thermal Hyperalgesia

The treatment of the naïve mice with COL-3 $40 \mathrm{mg} /$ $\mathrm{kg}$ by oral gavage daily for 5 consecutive days did not 
Table 1. PCR primer sequences of cyclophilin, CD11b, cytokines and chemokines

\begin{tabular}{|c|c|c|c|}
\hline Gene & Polarity & Sequence $5^{\prime}$ to $3^{\prime}$ & GenBank No. \\
\hline Cyclophilin & $\begin{array}{l}\text { Sense } \\
\text { Antisense }\end{array}$ & $\begin{array}{l}\text { GCTTTTCGCCGCTTGCT } \\
\text { CTCGTCATCGGCCGTGAT }\end{array}$ & X52803 \\
\hline CD11b & $\begin{array}{l}\text { Sense } \\
\text { Antisense }\end{array}$ & $\begin{array}{l}\text { TGCTTACCTGGGTTATGCTTCTG } \\
\text { CCGAGGTGCTCCTAAAACCA }\end{array}$ & NM_008401 \\
\hline IFN- $\gamma$ & $\begin{array}{l}\text { Sense } \\
\text { Antisense }\end{array}$ & $\begin{array}{l}\text { ACAATGAACGCTACACACTGCAT } \\
\text { TGGCAGTAACAGCCAGAAACA }\end{array}$ & NM_008337 \\
\hline IL-1 $\beta$ & $\begin{array}{l}\text { Sense } \\
\text { Antisense }\end{array}$ & $\begin{array}{l}\text { TGGTGTGTGACGTTCCCATT } \\
\text { CAGCACGAGGCTTTTTTGTTG }\end{array}$ & NM_010554 \\
\hline IL-6 & $\begin{array}{l}\text { Sense } \\
\text { Antisense }\end{array}$ & $\begin{array}{l}\text { ACAAGTCGGAGGCTTAATTACACAT } \\
\text { TTGCCATTGCACAACTCTTTTC }\end{array}$ & NM_031168 \\
\hline IL-10 & $\begin{array}{l}\text { Sense } \\
\text { Antisense }\end{array}$ & $\begin{array}{l}\text { CAGCCGGGAAGACAATAACTG } \\
\text { CCGCAGCTCTAGGAGCATGT }\end{array}$ & NM_010548 \\
\hline TNF- $\alpha$ & $\begin{array}{l}\text { Sense } \\
\text { Antisense }\end{array}$ & $\begin{array}{l}\text { GGCTGCCCCGACTACGT } \\
\text { GACTTTCTCCTGGTATGAGATAGCAAA }\end{array}$ & NM_013693 \\
\hline CCL2 & $\begin{array}{l}\text { Sense } \\
\text { Antisense }\end{array}$ & $\begin{array}{l}\text { GGCTCAGCCAGATGCAGTTAAC } \\
\text { CCTACTCATTGGGATCATCTTGCT }\end{array}$ & NM_011333 \\
\hline CXCL10 & $\begin{array}{l}\text { Sense } \\
\text { Antisense }\end{array}$ & $\begin{array}{l}\text { GACGGTCCGCTGCAACTG } \\
\text { GCTTCCCTATGGCCCTCATT }\end{array}$ & NM_021274 \\
\hline CXC3CL1 & $\begin{array}{l}\text { Sense } \\
\text { Antisense }\end{array}$ & $\begin{array}{l}\text { ATTGTCCTGGAGACGACACAGC } \\
\text { TTGCCACCATTTTTAGTGAGGG }\end{array}$ & NT_078575 \\
\hline
\end{tabular}

GenBank accession numbers of sequences used for primer design.

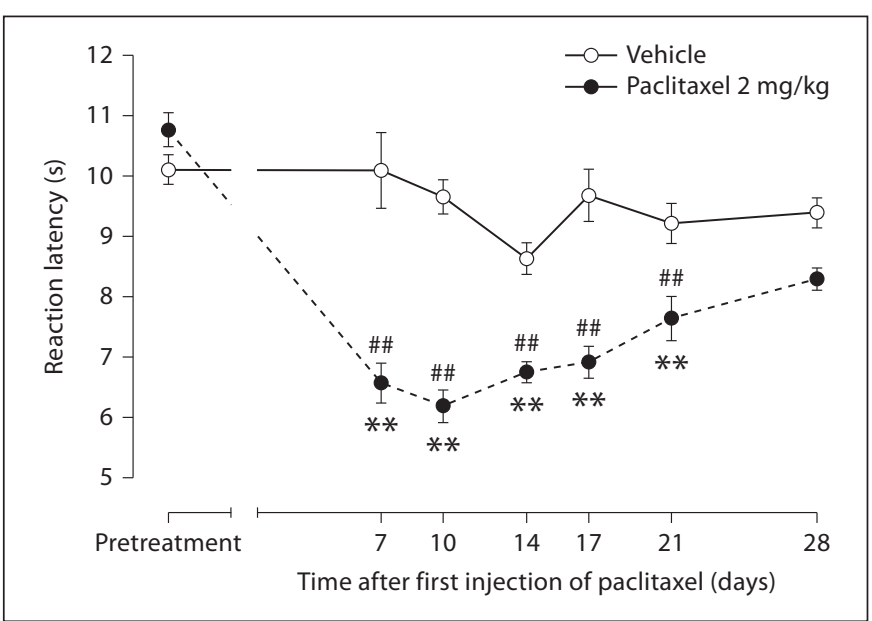

Fig. 1. Paclitaxel-induced thermal hyperalgesia in $B A L B / c$ mice. Time course of the reaction latency time to the hot plate test after the administration of paclitaxel $2 \mathrm{mg} / \mathrm{kg}$ or its vehicle. Each point represents the mean \pm SEM of the values obtained from 14-16 animals. ${ }^{* *} \mathrm{p}<0.01$ compared to drug vehicle on the same day after treatment; ${ }^{\# \#} \mathrm{p}<0.01$ compared to pretreatment values.

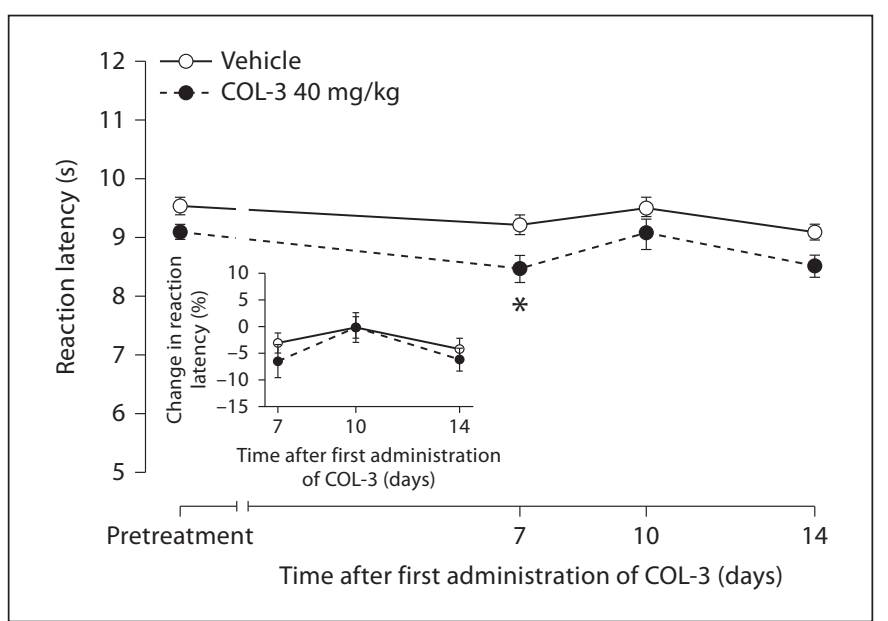

Fig. 2. Time course of the reaction latency time to the hot plate test after the administration of COL-3 $40 \mathrm{mg} / \mathrm{kg}$ or its vehicle. Each point represents the mean \pm SEM of the values obtained from 19-21 animals. There were no statistically significant differences in the percentage change in reaction latency between the COL-3-treated and the vehicle-treated animals. ${ }^{*} \mathrm{p}<0.05 \mathrm{com}$ pared to drug vehicle on the same day after treatment.

Med Princ Pract 2013;22:35-41 
Fig. 3. Coadministration of COL-3 with paclitaxel protects against the development of paclitaxel-induced thermal hyperalgesia. Effects of coadministration of paclitaxel with COL-3 on the development of paclitaxel-induced thermal hyperalgesia in BALB/c mice. Each point represents the mean \pm SEM of the values obtained from 17-23 animals. ${ }^{* *} \mathrm{p}<0.01$ compared to control mice; \#\# $\mathrm{p}<0.01$ compared to mice treated with paclitaxel plus vehicle.

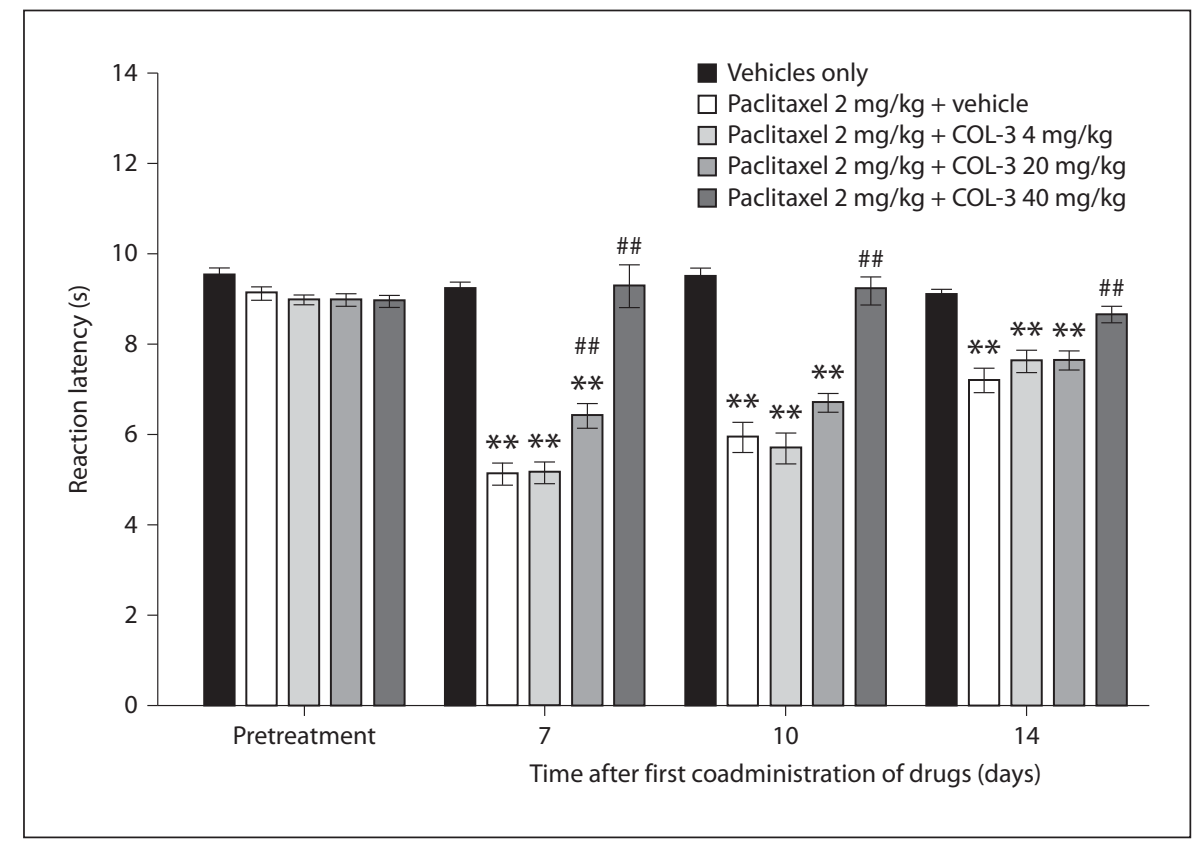

cause any significant changes to the reaction latency compared to the pretreatment baseline values $(\mathrm{p}>0.05$; fig. 2). The COL-3-treated mice showed a slightly lower reaction latency compared to the vehicle-treated mice only on day 7 ( $\mathrm{p}<0.05$; fig. 2 ). However, the percentage changes from pretreatment latencies were not different between the vehicle-treated and the COL-3-treated mice ( $p>0.05$; fig. 2 insert), indicating that COL-3 did not affect the mice's reaction latencies to thermal nociception.

The mice treated with paclitaxel plus COL-3 (40 mg/ $\mathrm{kg}$ ) had reaction latency times similar to the vehicle-onlytreated control animals, which were significantly higher than those of the mice treated with paclitaxel only ( $\mathrm{p}<$ 0.01 ; fig. 3). However, the reaction latency times of the mice treated with paclitaxel plus lower doses of COL-3 (4 or $20 \mathrm{mg} / \mathrm{kg}$ ) were significantly lower than those of the vehicle-only-treated control animals $(\mathrm{p}<0.01)$, but the reaction latency of the mice treated with paclitaxel plus COL-3 at $20 \mathrm{mg} / \mathrm{kg}$ was significantly higher on day 7 after the first drug administration than those treated with paclitaxel alone ( $\mathrm{p}<0.01$; fig. 3$)$.

\section{Effects of COL-3 on Cytokine, Chemokine and CD11b}

Transcript Levels during Paclitaxel-Induced Thermal

Hyperalgesia

Treatment with either paclitaxel alone or the coadministration of paclitaxel plus COL-3 caused a significant

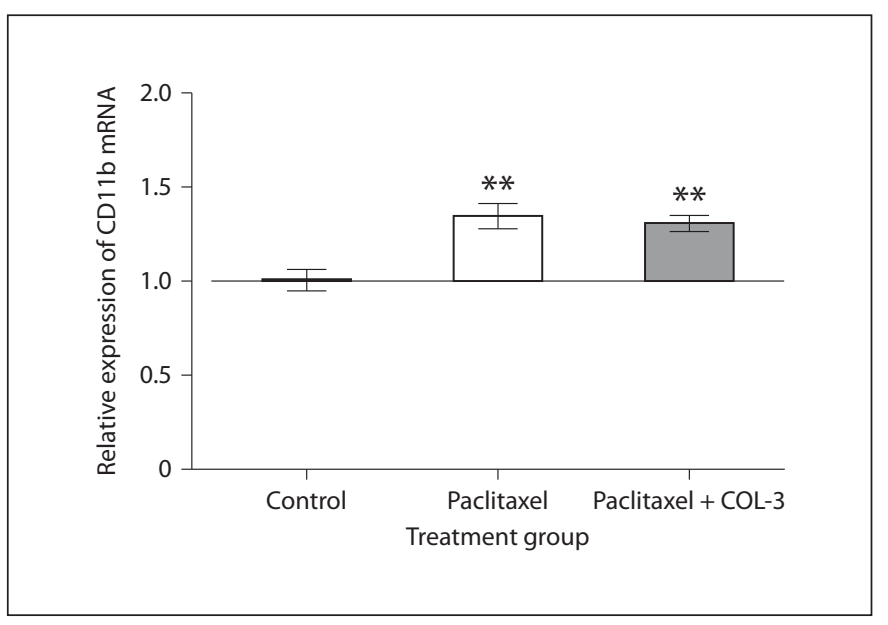

Fig. 4. Effects of coadministration of paclitaxel with COL-3 on relative $\mathrm{CD} 11 \mathrm{~b}$ mRNA expression in the brains of $\mathrm{BALB} / \mathrm{c}$ mice on day 7 after the first administration of drugs. Each point represents the mean \pm SEM of the values obtained from 5-6 animals. ${ }^{* *} \mathrm{p}<0.01$ compared to control mice.

increase in CD11b transcript levels (a marker for microglia activation) in the brain compared to the vehicle-only-treated controls ( $\mathrm{p}<0.01$; fig. 4). However, treatment with paclitaxel or the coadministration of paclitaxel plus COL-3 did not significantly affect the levels of CD11b transcripts in the spinal cord (data not shown). 


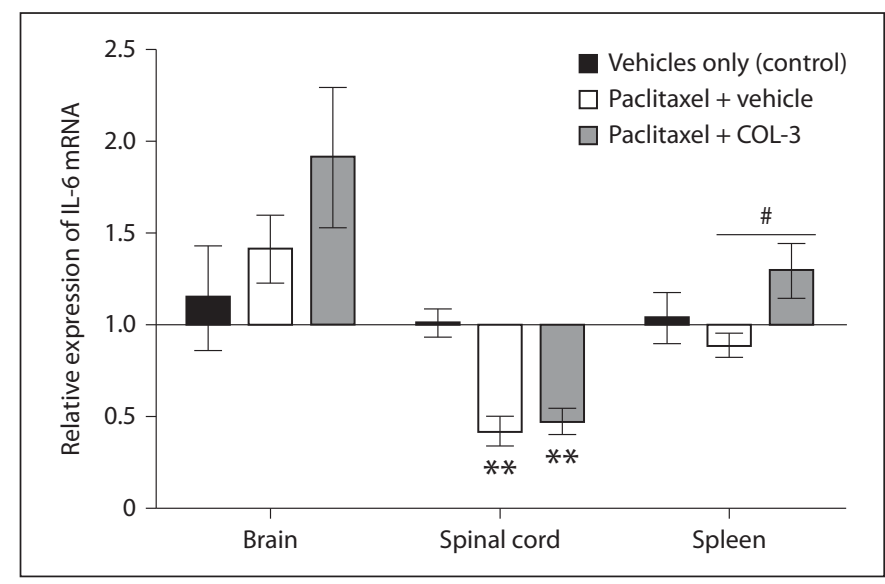

Fig. 5. Effects of coadministration of paclitaxel with COL-3 on relative IL- 6 mRNA expression in the brains, spinal cords and spleens of BALB/c mice on day 7 after the first administration of drugs. Each point represents the mean \pm SEM of the values obtained from $4-6$ animals. ${ }^{* *} \mathrm{p}<0.01$ compared to control mice; ${ }^{\#} \mathrm{p}<0.05$ compared to mice treated with paclitaxel plus vehicle.

Treatment with either paclitaxel alone or the coadministration of paclitaxel plus COL-3 caused a significant reduction in IL- 6 transcript levels in the spinal cord compared to the vehicle-only-treated controls ( $\mathrm{p}<0.01$; fig. 5). The spleens of the mice treated with paclitaxel plus COL3 had significantly higher levels of IL- 6 transcripts compared to those of the mice treated with paclitaxel only ( $\mathrm{p}<0.05$; fig. 5). However, treatment with paclitaxel or the coadministration of paclitaxel plus COL-3 did not significantly affect the levels of the transcripts of the other cytokines (IFN- $\gamma$, IL-1 $\beta$, IL-10 and TNF- $\alpha$ ) in the brain, spinal cord or spleen (data not shown).

The brains of the mice treated with paclitaxel plus COL-3 had significantly low levels of CX3CL1 transcripts compared to those of the mice treated with paclitaxel plus vehicle or vehicle only ( $p<0.05$; fig. 6 ). On the other hand, treatment of the mice with paclitaxel alone or the coadministration of paclitaxel plus COL-3 did not significantly affect the levels of the transcripts of the other chemokines (CCL2 and CXCL10) in the brain, spinal cord or spleen (data not shown).

\section{Discussion}

This study showed for the first time that the MMP inhibitor COL-3 protects against the development of paclitaxel-induced thermal hyperalgesia. It also provided evi-

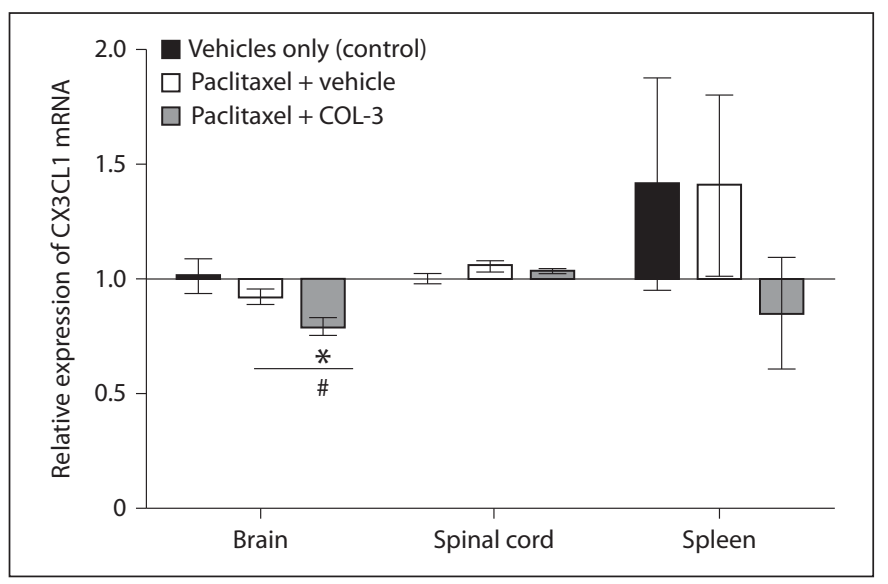

Fig. 6. Effects of coadministration of paclitaxel with COL-3 on relative CX3CL1 mRNA expression in the brains, spinal cords and spleens of BALB/c mice on day 7 after the first administration of drugs. Each point represents the mean \pm SEM of the values obtained from $4-6$ animals. ${ }^{*} \mathrm{p}<0.05$ compared to control mice; ${ }^{\#} \mathrm{p}<0.05$ compared to mice treated with paclitaxel plus vehicle.

dence that the coadministration of COL-3 with paclitaxel increased IL- 6 transcripts in the spleen and decreased the transcripts of CX3CL1 in the brains of mice compared to treatment with paclitaxel only.

Paclitaxel is a standard treatment, often in combination with carboplatin, for various cancers including lung, breast and ovarian cancer. However, its use is limited by the development of peripheral neuropathy which is painful in some patients [4]. Treatment with paclitaxel has been previously shown to produce painful neuropathy, including thermal hyperalgesia, in mice [6].

Currently, there are no clinically available effective treatments for the prevention or treatment of this doselimiting painful neuropathy. In order to find possible drugs for the prevention of PINP considerable research is being undertaken to understand its pathophysiology. The mechanism for the development of PINP is not clear, but various factors have been proposed, including the disruption of microtubule functions in axons, the generation of free radicals, glial cell activation, cytokine production and the upregulation of MMPs and activation of proteinase-activated receptors $[3,8-13,21]$.

We found that COL-3, a potent MMP inhibitor, prevented the development of paclitaxel-induced thermal hyperalgesia, suggesting that MMPs are a plausible target for the prevention of PINP. Minocycline, a tetracycline antibiotic with anti-inflammatory activities including the inhibition of MMPs, though less potent than 
COL-3, has been reported to prevent the development of PINP, most probably via its inhibitory effects on glial cell activation and macrophage infiltration into the dorsal root ganglion $[9,21]$. However, the administration of minocycline over long periods of time may result in the emergence of bacterial resistance to tetracycline antibiotics and also lead to undesirable side effects through the killing of commensal bacteria. COL-3, on the other hand, does not have antibiotic activities because it lacks the dimethylamino group from the carbon-4 position, the side chain, which is required for the antimicrobial activity of tetracyclines [14, 22]. Apart from COL-3 being an MMP inhibitor, recent data suggest that it can also inhibit serine proteinases [23]. This activity of the drug could also contribute to its protective effects against the development of PINP, since serine proteinase-activated receptors have recently been implicated in the development of PINP [12].

Glial cells, cytokines and chemokines have also been implicated in the development of neuropathic pain including PINP $[10,11]$. In BALB/c mice, we observed an increase in CD11b transcripts in the brains, but not in the spinal cords, of paclitaxel-treated animals, which was not affected by the coadministration with COL-3. These data suggest that the protective effects of COL-3 against the development of PINP were not mediated via modulating microglia activity in the brain or spinal cord. We did not observe an increase in cytokines in the spleen, brain or spinal cord after treatment with paclitaxel. This is in agreement with the study by Zhang et al. [9], where no increase was observed in the proinflammatory cytokine levels in the spinal cords of animals with PINP. Interestingly, the coadministration of COL-3 with paclitaxel increased IL- 6 transcripts in the spleen. However, the reduced expression of IL- 6 transcripts in the spinal cords of the mice treated with paclitaxel alone was not prevented by the coadministration with COL-3. This suggests that the protective effects of COL-3 against the developof IL- 6 in the periphery, but not in the spinal cord. The administration of IL- 6 has been reported to protect against the development of PINP [5]. However, IL-6 is a cytokine that has pleiotropic activity, including neurotrophic and pro- and anti-inflammatory activities depending on the conditions [24]. Another interesting obthe chemokine CX3CL1 (also known as fractalkine) in the brains of the mice treated with both COL-3 and paclitaxel. CX3CL1 has been reported to mediate neuropathic pain [25]. Thus, the reduction of CX3CL1 expres-

sion could also have contributed to the protective effects of COL-3 against the development of PINP.

COL-3 also has antitumor activities $[26,27]$ and it has been evaluated in phase II clinical trials for the treatment of cancers such as sarcomas [28-30]. Interestingly, the dose of COL-3, $40 \mathrm{mg} / \mathrm{kg}$, which we found to be effective for preventing paclitaxel-induced thermal hyperalgesia, was closer to the dose of COL-3 used for treating sarcomas, $50 \mathrm{mg} / \mathrm{kg}[28,29]$. Taking into consideration that COL-3 shows potential to improve the tolerability of paclitaxel, it would also be worth evaluating the possibility of increased efficacy against tumors by combining COL-3 with paclitaxel. If effective, this would present a double advantage of reducing side effects and increasing antitumor efficacy.

\section{Conclusion}

Our results showed that the MMP inhibitor COL-3 prevented the development of paclitaxel-induced thermal hyperalgesia. Therefore, this drug warrants further research as a potential candidate to be used in combination with paclitaxel to prevent the development of painful peripheral neuropathy.

\section{Acknowledgements}

This study was supported by grants PT01/11, GM01/01 and GM01/05 from Kuwait University Research Administration. We are grateful to Galderma, Research and Development SNC, Les Templier, France for the generous gift of COL-3. We thank Princy Susan Geevarghese Mathew for her technical assistance and the staff from the Animal Resources Center, HSC, Kuwait University for their support. ment of PINP could have been partly due to an increase servation was the specific decrease in the transcripts of

References
1 Luqmani YA: Mechanisms of drug resistance in cancer chemotherapy. Med Princ Pract 2005; 14(suppl 1):35-48.

-2 Cata JP, Weng HR, Lee BN, Reuben JM, Dougherty PM: Clinical and experimental findings in humans and animals with chemotherapy-induced peripheral neuropathy. Minerva Anestesiol 2006;72:151-169.

$\checkmark 3$ Polomano RC, Bennett GJ: Chemotherapyevoked painful peripheral neuropathy. Pain Med 2001;2:8-14.

$\checkmark 4$ Dougherty PM, Cata JP, Cordella JV, Burton A, Weng HR: Taxol-induced sensory disturbance is characterized by preferential impairment of myelinated fiber function in cancer patients. Pain 2004;109:132-142. 
$\checkmark 5$ Callizot N, Andriambeloson E, Glass J, Revel M, Ferro P, Cirillo R, Vitte PA, Dreano M: Interleukin- 6 protects against paclitaxel, cisplatin and vincristine-induced neuropathies without impairing chemotherapeutic activity. Cancer Chemother Pharmacol 2008;62: 995-1007.

- 6 Nieto FR, Entrena JM, Cendan CM, Pozo ED, Vela JM, Baeyens JM: Tetrodotoxin inhibits the development and expression of neuropathic pain induced by paclitaxel in mice. Pain 2008;137:520-531.

7 Smith BH, Elliott AM, Hannaford PC: Is chronic pain a distinct diagnosis in primary care? Evidence arising from the Royal College of General Practitioners' Oral Contraception study. Fam Pract 2004;21:66-74.

-8 Peters CM, Jimenez-Andrade JM, Kuskowski MA, Ghilardi JR, Mantyh PW: An evolving cellular pathology occurs in dorsal root ganglia, peripheral nerve and spinal cord following intravenous administration of paclitaxel in the rat. Brain Res 2007;1168:46-59.

9 Zhang H, Yoon SY, Dougherty PM: Evidence that spinal astrocytes but not microglia contribute to the pathogenesis of Paclitaxel-induced painful neuropathy. J Pain 2012;13: 293-303.

10 Burgos E, Gomez-Nicola D, Pascual D, Martin MI, Nieto-Sampedro M, Goicoechea C: Cannabinoid agonist WIN 55,212-2 prevents the development of paclitaxel-induced peripheral neuropathy in rats. Possible involvement of spinal glial cells. Eur J Pharmacol 2012;682.62-72.

11 Ledeboer A, Jekich BM, Sloane EM, Mahoney JH, Langer SJ, Milligan ED, Martin D, Maier SF, Johnson KW, Leinwand LA, Chavez RA, Watkins LR: Intrathecal interleukin-10 gene therapy attenuates paclitaxelinduced mechanical allodynia and proinflammatory cytokine expression in dorsal root ganglia in rats. Brain Behav Immun 2007;21:686-698.
12 Chen Y, Yang C, Wang ZJ: Proteinase-activated receptor 2 sensitizes transient receptor potential vanilloid 1 , transient receptor potential vanilloid 4, and transient receptor potential ankyrin 1 in paclitaxel-induced neuropathic pain. Neuroscience 2011;193:440451.

13 Nishida K, Kuchiiwa S, Oiso S, Futagawa T, Masuda S, Takeda Y, Yamada K: Up-regulation of matrix metalloproteinase-3 in the dorsal root ganglion of rats with paclitaxel induced neuropathy. Cancer Sci 2008;99: 1618-1625.

14 Golub LM, Ramamurthy NS, McNamara TF, Greenwald RA, Rifkin BR: Tetracyclines inhibit connective tissue breakdown: new therapeutic implications for an old family of drugs. Crit Rev Oral Biol Med 1991;2:297321.

15 Greenwald RA, Golub LM, Ramamurthy NS, Chowdhury M, Moak SA, Sorsa T: In vitro sensitivity of the three mammalian collagenases to tetracycline inhibition: relationship to bone and cartilage degradation. Bone 1998;22:33-38

16 Gu Y, Lee HM, Golub LM, Sorsa T, Konttinen YT, Simon SR: Inhibition of breast cancer cell extracellular matrix degradative activity by chemically modified tetracyclines. Ann Med 2005;37:450-460.

17 Zimmermann M: Ethical guidelines for investigations of experimental pain in conscious animals. Pain 1983;16:109-110.

-18 Masocha W, Robertson B, Rottenberg ME, Mhlanga J, Sorokin L, Kristensson K: Cerebral vessel laminins and IFN-gamma define Trypanosoma brucei brucei penetration of the blood-brain barrier. J Clin Invest 2004; 114:689-694.

19 Masocha W: Systemic lipopolysaccharide (LPS)-induced microglial activation results in different temporal reduction of CD200 and CD200 receptor gene expression in the brain. J Neuroimmunol 2009;214:78-82.

-20 Livak KJ, Schmittgen TD: Analysis of relative gene expression data using real-time quantitative PCR and the 2(-delta delta C(T)) Method. Methods 2001;25:402-408.
21 Liu CC, Lu N, Cui Y, Yang T, Zhao ZQ, Xin WJ, Liu XG: Prevention of paclitaxel-induced allodynia by minocycline: effect on loss of peripheral nerve fibers and infiltration of macrophages in rats. Mol Pain 2010; 6:76.

-22 Acharya MR, Venitz J, Figg WD, Sparreboom A: Chemically modified tetracyclines as inhibitors of matrix metalloproteinases. Drug Resist Updat 2004;7:195-208.

23 Gu Y, Lee HM, Simon SR, Golub LM: Chemically modified tetracycline-3 (CMT-3): a novel inhibitor of the serine proteinase, elastase. Pharmacol Res 2011;64:595-601.

24 Spooren A, Kolmus K, Laureys G, Clinckers R, De Keyser J, Haegeman G, Gerlo S: Interleukin-6, a mental cytokine. Brain Res Rev 2011;67:157-183.

25 Milligan ED, Sloane EM, Watkins LR: Glia in pathological pain: a role for fractalkine. J Neuroimmunol 2008;198:113-120.

-26 Lokeshwar BL: Chemically modified nonantimicrobial tetracyclines are multifunctional drugs against advanced cancers. Pharmacol Res 2011;63:146-150.

27 Richards C, Pantanowitz L, Dezube BJ: Antimicrobial and non-antimicrobial tetracyclines in human cancer trials. Pharmacol Res 2011;63:151-156.

28 Chu QS, Forouzesh B, Syed S, Mita M, Schwartz G, Cooper J, Curtright J, Rowinsky EK: A phase II and pharmacological study of the matrix metalloproteinase inhibitor (MMPI) COL-3 in patients with advanced soft tissue sarcomas. Invest New Drugs 2007; 25:359-367.

29 Dezube BJ, Krown SE, Lee JY, Bauer KS, Aboulafia DM: Randomized phase II trial of matrix metalloproteinase inhibitor COL-3 in AIDS-related Kaposi's sarcoma: an AIDS Malignancy Consortium Study. J Clin Oncol 2006;24:1389-1394.

30 Fingleton B: CMT-3. CollaGenex. Curr Opin Investig Drugs 2003;4:1460-1467. 